\title{
Monitored anesthesia care for great saphenous vein stripping surgery with target controlled infusion of propofol and remifentanil: a prospective study
}

\author{
Sooyoung Cho, Jong In Han, Hee Jung Baik, Dong Yeon Kim, and \\ Eun Hee Chun \\ Department of Anesthesiology and Pain Medicine, Ewha Womans University School of Medicine, Seoul, Korea
}

\begin{abstract}
Background: The aim of this study was to determine the appropriate target concentrations at the effect site of propofol and remifentanil when deep sedation was achieved by monitored anesthesia care (MAC) anesthesia and related respiratory depression during vein stripping surgery for varicose veins.

Methods: In total, 51 adult patients who were scheduled for varicose vein stripping surgery were sedated with propofol and remifentanil during the surgery, after administration of midazolam. Target concentrations at the effect site of the two drugs were changed based on the patient's status. Respiratory support was applied in the order of oxygen supply, chin lift, and assisted mask ventilation. Target concentrations at the effect site of propofol and remifentanil, the need for respiratory support, and a six-point rating scale satisfaction score were the outcome measurements.

Results: Only one patient did not require oxygen, eight patients needed oxygen alone, 22 patients required use of the chin lift technique, and 20 patients were assisted with mask ventilation. There was no significant difference in the target concentration of propofol or remifentanil between the patients who required mask ventilation and those who did not. Fifty of the 51 patients reported a satisfaction score of 6 .

Conclusions: Although MAC using low target concentrations of propofol and remifentanil during vein stripping surgery was satisfactory to patients, close observation regarding the need for respiratory assistance was necessary.
\end{abstract}

Key Words: Deep sedation, Propofol, Remifentanil, Respiration.

Corresponding author: Jong In Han, M.D., Ph.D.

Department of Anesthesiology and Pain Medicine, Ewha Womans University School of Medicine, 1071 Anyangcheon-ro, Yangcheon-gu, Seoul 07985, Korea

Tel: 82-2-2650-5285, Fax: 82-2-2655-2924

E-mail: hanji@ewha.ac.kr

Received: July 13, 2015.

Revised: October 14, 2015.

Accepted: October 22, 2015.

Korean J Anesthesiol 2016 April 69(2): 155-160

http://dx.doi.org/10.4097/kjae.2016.69.2.155

\section{Introduction}

Great or small saphenous vein stripping is a commonly performed surgical procedure as a treatment for varicose veins of the lower extremity. There are several anesthetic methods, including general anesthesia, neuraxial block, and peripheral nerve blocks, such as femoral nerve block, popliteal nerve block, and posterior cutaneous nerve block [1-4]. Monitored anesthesia care (MAC) with local anesthesia is another option for patients undergoing vein stripping.

(c) This is an open-access article distributed under the terms of the Creative Commons Attribution Non-Commercial License (http://creativecommons.org/ licenses/by-nc/4.0/), which permits unrestricted non-commercial use, distribution, and reproduction in any medium, provided the original work is properly cited. 
This surgery is usually performed on an ambulatory basis, because it typically causes minor surgical trauma and low postoperative pain [5]. Thus, many surgeons and anesthesiologists prefer MAC with local anesthesia or peripheral nerve block rather than general anesthesia or neuraxial block, due to the faster recovery from anesthesia and earlier discharge from the hospital $[1,6]$.

Propofol has a rapid onset time and short-acting properties. However, propofol cannot be used alone because it has no analgesic effect [7]. Remifentanil, which can provide intense analgesia, is an ultra-short-acting opioid and has a rapid onset time, so it can be controlled easily when infused continuously [8]. Thus, the combination of propofol and remifentanil is widely used in MAC. To provide precise delivery of these drugs, target controlled infusion (TCI) systems have been provided by several manufacturers. The device automatically calculates the infusion rate of a drug in real time, based on pharmacokinetics with the patient's demographic data (e.g., weight, height, and age). The device enables precise control of the drug level (the target concentration) in the plasma (Cp) or at the brain effect site (Ce). The anesthesiologist may change the target concentration according to the status of the patient during the procedure [9].

Today, sedation during various procedures, including minor operations, endoscopy, angiographic intervention, and dental procedures, is often performed by the procedural operator, who may be a surgeon, endoscopist, radiologist, or dentist. These physicians also use propofol and remifentanil when they sedate patients. However, deep sedation or MAC can create several problems, such as respiratory depression, cardiovascular events, and inadequate anesthesia [10]. The most important issue is respiration because it can result in serious complications or cause permanent sequelae, such as hypoxic brain damage and even death. Thus, achieving an appropriate depth of sedation and continuous monitoring of the patient's condition are vital.

Although vein stripping surgery typically only involves a small incision site at the level of the femoral vein, the sphere of vein manipulation extends into the lower leg. Because infiltration of local anesthetics at the incision site cannot cover the whole area of vein manipulation and can cause pain and discomfort, deeper sedation than conscious sedation is necessary during such vein stripping surgery. We sought to determine the required target concentration at the effect site of propofol and remifentanil when deep sedation was achieved with MAC anesthesia and related respiratory depression during varicose vein stripping surgery.

\section{Materials and Methods}

This research was approved by the Institutional Review Board of the hospital. After explaining the purpose and methods of the study to the patients, 51 adult patients provided written consent. They were of American Society of Anesthesiologists (ASA) physical status I-II and were to undergo great saphenous vein stripping surgery. The patients were aged from 20 to 70 years. Exclusion criteria were a history of drug abuse or chronic sedative use, high cardiovascular risk, significant pulmonary disease, need for the prone position (scheduled together with small saphenous vein stripping), and known allergies to any medication we intended to use.

After the patient arrived in the operating room, standard monitoring, including non invasive arterial pressure (NIBP), electrocardiography (ECG), heart rate (HR), and pulse oximetry $\left(\mathrm{SpO}_{2}\right)$, was started. Additionally, a bispectral index (BIS) monitor (BIS, Covidien, MA, USA) was applied and an end-tidal $\mathrm{CO}_{2}$ $\left(\mathrm{ETCO}_{2}\right)$ sampling line was placed. When the anesthesiologist confirmed that the vital signs were stable, $500 \mathrm{ml}$ of crystalloid fluid (normal saline or Hartmann's solution) was dripped intravenously (IV). Without supplying oxygen, $0.05 \mathrm{mg} / \mathrm{kg}$ midazolam and $0.2 \mathrm{mg}$ glycopyrrolate were injected intravenously.

At $5 \mathrm{~min}$, propofol infusion was started using a TCI pump (Orchestra base primea, Fresenius Kabi, Bad Homburg, Germany). The first patient's initial Ce of propofol was set to 0.9 $\mu \mathrm{g} / \mathrm{ml}$, slightly lower than the plasma concentration required for sedation [11]. From the second patient, the initial Ce for propofol started from the last patient's Ce at the end of surgery. Simultaneously, draping of the operation site was performed and the anesthesiologist changed the Ce of propofol by $0.2 \mu \mathrm{g} / \mathrm{ml}$ to maintain BIS values within 55-75. Remifentanil infusion was started 2 min before the start of surgery, and 2\% lidocaine skin infiltration was initiated immediately before the inguinal incision. The first patient's initial Ce of remifentanil was set to 0.9 $\mathrm{ng} / \mathrm{ml}$, slightly lower than the plasma concentration for minor surgery [12]. In the same way as propofol, the last patient's Ce at the end of surgery determined the next patient's initial Ce. The anesthesiologist increased the Ce of remifentanil by $0.2 \mathrm{ng} / \mathrm{ml}$ if the patient showed a pain response, such as moving, moaning, frowning, or an increase in mean arterial pressure (MAP) or HR by more than $20 \%$ from baseline. In contrast, when MAP or HR was decreased by $20 \%$ or more from baseline, the Ce of remifentanil was lowered by $0.2 \mathrm{ng} / \mathrm{ml}$.

Respiration assistance was started immediately if needed at any point after midazolam administration, and was performed as follows (Fig. 1): 1. Oxygen $\left(\mathrm{O}_{2} ; 6 \mathrm{~L} / \mathrm{min}\right)$ supply was started if $\mathrm{SpO}_{2}$ was $<95 \%, 2$. the chin lift (CL) technique was applied additionally if $\mathrm{SpO}_{2}$ continued to be $<95 \%$ despite $\mathrm{O}_{2}$ supply for $30 \mathrm{~s}$, there was a progressive decrease in $\mathrm{SpO}_{2}, \mathrm{ETCO}_{2}>50$ $\mathrm{mmHg}$, or respiration rate $(\mathrm{RR})<10$ breaths/min, and 3 . if hypoventilation continued, assisted ventilation (AV) with a mask was started. In all cases, advanced respiratory support devices, including a laryngeal mask, airway and endotracheal tubes, and 


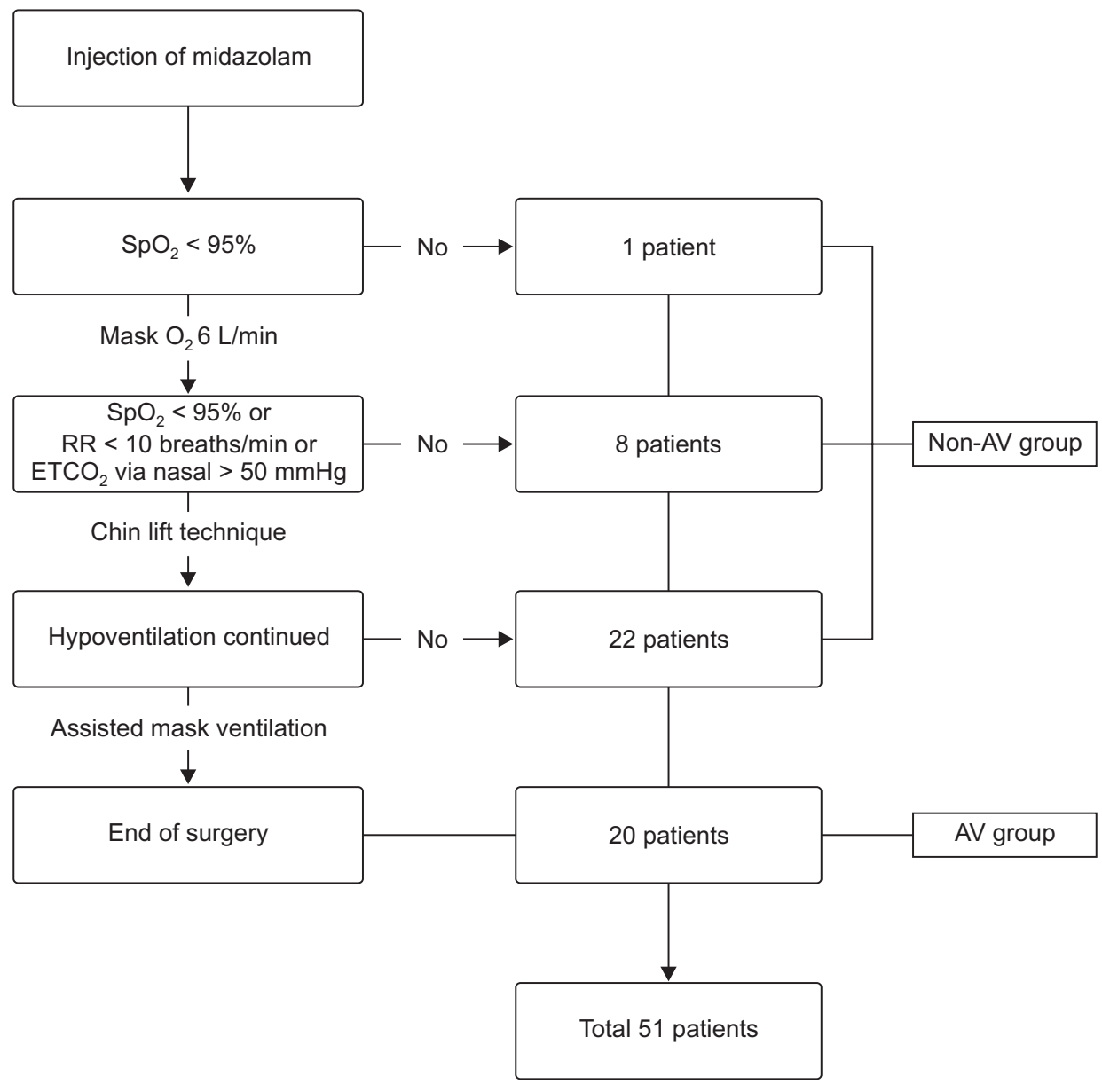

Fig. 1. Flow chart of respiratory support during surgery. $\mathrm{SpO}_{2}$ : pulse oximetry. RR: respiration rate. $\mathrm{ETCO}_{2}$ : end-tidal $\mathrm{CO}_{2}$. a laryngoscope for intubation, were available for emergency use in cases of difficult mask ventilation.

At the end of surgery, Ce and the infusion rates of propofol and remifentanil at that time were recorded and all infusions were stopped. Total amounts of infused propofol and remifentanil were recorded. The most advanced step of respiration assist (self, $\mathrm{O}_{2}, \mathrm{CL}$, or AV) was recorded. The maximal Ce and infusion rates of propofol and remifentanil during the operation were recorded. The maximum Ce of propofol was defined as the highest Ce after the moment the patient reached steady state with a wellmaintained BIS and no moving or awakening for longer than 5 min when draping. This defining process was required due to the need to titrate Ce. The former patient's last Ce determined the next patient's initial $\mathrm{Ce}$, and this level of Ce could be high for the next patient. Thus, if the maximum Ce was determined without titration, the initial Ce could be the maximum $\mathrm{Ce}$ in such patients. Also, in the case of remifentanil, the titration was done after skin incision and the maximal Ce of remifentanil was defined as the highest $\mathrm{Ce}$ after reaching steady state (the patient showed no pain response and MAP and HR were within $20 \%$ of baseline) for longer than 5 min during the operation.

When the patient awoke and the anesthesiologist confirmed self-respiration and vital signs, the patient was moved to the post-anesthetic care unit (PACU). The anesthesiologist checked for intraoperative awareness, postoperative nausea, vomiting, and dizziness. Patient satisfaction was assessed in PACU with a six-point Likert scale, from 1 , very dissatisfied, to 6 , very satisfied [13].

After the surgery, the patients were allocated to two groups. One was the group of patients who did not need assisted mask ventilation (non-AV group) and the other was the group of patients who were assisted by mask ventilation (AV group; Fig. 1). We compared the maximum Ce values of propofol and remifentanil and adverse events between two groups.

We assumed that the AV group would have twice the Ce of the non-AV group, based on previous studies [14-16]. A power analysis based on $90 \%$ power with a type I error of 0.05 determined that we needed to include 23 patients in each group. Assuming a $10 \%$ drop-out rate, it was calculated that 51 patients would be required. 
Data analyses were conducted with the SPSS software (version 20.0, IBM Corp., Armonk, NY, USA). Student's t-test was used for continuous variables and the $\chi^{2}$ test was used for categorical variables. A P value $<0.05$ was considered to indicate statistical significance.

\section{Results}

One patient (2\%) did not request $\mathrm{O}_{2}$ and $8(16 \%)$ patients needed only $\mathrm{O}_{2}$ until the end of surgery. The anesthesiologist performed the chin lift technique in 22 (43\%) patients and assisted mask ventilation was used with 20 (39\%) patients (Fig. 1). Thus, 31 patients were included in the non-AV group and 20 patients were in the AV group. The mean age of patients in the non-AV group was 53.6 years, significantly older than the AV group, where patients were aged 46.3 years. There was no significant difference in other aspects of other demographics (Table 1).

The maximum Ce values of propofol in the non-AV group and the AV group were $1.14 \pm 0.48 \mu \mathrm{g} / \mathrm{ml}(2.97 \pm 1.29 \mathrm{mg} / \mathrm{kg} / \mathrm{h})$ and $1.33 \pm 0.44 \mathrm{ng} / \mathrm{ml}(3.53 \pm 1.37 \mathrm{mg} / \mathrm{kg} / \mathrm{h})$, respectively. The maximum Ce values of remifentanil in the non-AV group and $\mathrm{AV}$ group were $1.41 \pm 0.40 \mathrm{ng} / \mathrm{ml}(0.06 \pm 0.02 \mu \mathrm{g} / \mathrm{kg} / \mathrm{min})$ and $1.54 \pm 0.38 \mathrm{ng} / \mathrm{ml}(0.07 \pm 0.02 \mu \mathrm{g} / \mathrm{kg} / \mathrm{min})$, respectively. There

Table 1. Demographic Data

\begin{tabular}{lccc}
\hline & $\begin{array}{c}\text { Non-AV group } \\
(\mathrm{n}=31)\end{array}$ & $\begin{array}{c}\text { AV group } \\
(\mathrm{n}=20)\end{array}$ & P value \\
\hline Age $(\mathrm{yr})$ & $53.6 \pm 10.7$ & $46.3 \pm 9.9$ & 0.019 \\
Sex $(\mathrm{M} / \mathrm{F})$ & $14 / 17$ & $4 / 16$ & 0.061 \\
Height $(\mathrm{cm})$ & $166.0 \pm 8.7$ & $163.2 \pm 8.2$ & 0.258 \\
Weight $(\mathrm{kg})$ & $64.7 \pm 11.5$ & $60.5 \pm 9.7$ & 0.180 \\
BMI $\left(\mathrm{kg} / \mathrm{m}^{2}\right)$ & $23.4 \pm 2.5$ & $22.6 \pm 2.7$ & 0.347 \\
ASA classification $(\mathrm{I} / \mathrm{II})$ & $11 / 20$ & $11 / 9$ & 0.139 \\
Operation time $(\mathrm{min})$ & $42.4 \pm 10.4$ & $44.8 \pm 17.1$ & 0.587 \\
Anesthesia time $(\mathrm{min})$ & $81.9 \pm 15.6$ & $80.5 \pm 19.7$ & 0.773 \\
\hline
\end{tabular}

Values are expressed as mean \pm standard deviation (SD) or numbers. BMI: body mass index, ASA: American Society of Anesthesiologists. was no significant difference between the groups (Table 2).

One patient experienced awareness during the operation. The satisfaction score of this patient was 2 and was 6 for all other patients. No patient complained of opioid side effects, such as nausea, vomiting, or dizziness.

\section{Discussion}

We sought to determine the required target concentrations at the effect site of propofol and remifentanil when an appropriate level of sedation was achieved by MAC anesthesia during varicose vein stripping surgery. The mean maximum Ce of propofol was $1.21 \mu \mathrm{g} / \mathrm{ml}(3.19 \mathrm{mg} / \mathrm{kg} / \mathrm{h})$ and the mean maximum Ce of remifentanil was $1.46 \mathrm{ng} / \mathrm{ml}(0.06 \mu \mathrm{g} / \mathrm{kg} / \mathrm{min})$.

Vein stripping surgery usually takes about $1 \mathrm{~h}$ or less and causes minimal blood loss, minimal surgical pain, and minor trauma. This is why such surgery is usually performed on an ambulatory basis. Armellin et al. [17] reported that deep sedation coupled with local anesthetic infiltration was a simple and reliable method for vein stripping in day surgery patients. Eikaas and Raeder [9] and Hong et al. [18] suggested that the combination of propofol and remifentanil was suitable for ambulatory surgery, due to the fast recovery and the low incidence of nausea and vomiting.

Usually, MAC is the method of choice for varicose vein stripping surgery in our hospital. There are three elements of MAC: safe sedation, control of patient anxiety, and pain control [19]. To satisfy these elements, an appropriate level of sedation is important [10]. Due to the wide surgical region involved along the femoral vein, deep sedation is necessary, rather than conscious sedation, during vein stripping surgery.

The ASA describes that conscious sedation secures a patent airway, but deep sedation may require airway support [20]. Thus, manual bagging by an anesthesiologist could be used and, occasionally, an airway device, such as intubation or supraglottic airway (laryngeal mask airway) may be necessary to maintain the upper airway. However, in our hospital, manual assist under

Table 2. Dose and Infusion Drug Data

\begin{tabular}{|c|c|c|c|}
\hline & $\begin{array}{l}\text { Non-AV group } \\
\quad(\mathrm{n}=31)\end{array}$ & $\begin{array}{l}\text { AV group } \\
(\mathrm{n}=20)\end{array}$ & $P$ value \\
\hline Midazolam (mg) & $3.12 \pm 0.54$ & $2.94 \pm 0.43$ & 0.209 \\
\hline Total infused propofol (mg) & $174.1 \pm 75.3$ & $173.5 \pm 61.9$ & 0.974 \\
\hline Total infused remifentanil $(\mu \mathrm{g})$ & $120.3 \pm 45.8$ & $139.4 \pm 51.2$ & 0.194 \\
\hline Lowest $\mathrm{SpO}_{2}(\%)$ & $93.3 \pm 1.4$ & $92.8 \pm 2.4$ & 0.386 \\
\hline Maximum Ce of propofol $(\mu \mathrm{g} / \mathrm{ml})$ & $1.14 \pm 0.48$ & $1.33 \pm 0.44$ & 0.179 \\
\hline Maximum rate of propofol (mg/kg/h) & $2.97 \pm 1.29$ & $3.53 \pm 1.37$ & 0.145 \\
\hline Maximum Ce of remifentanil (ng/kg) & $1.41 \pm 0.40$ & $1.54 \pm 0.38$ & 0.264 \\
\hline Maximum rate of remifentanil ( $\mu \mathrm{g} / \mathrm{kg} / \mathrm{min})$ & $0.06 \pm 0.02$ & $0.07 \pm 0.02$ & 0.101 \\
\hline
\end{tabular}

Values are expressed as mean \pm SD. Ce: target concentration at the effect site. 
deep sedation would be preferred, to avoid general anesthesia and intubation and the disadvantages of these devices, including sore throat, possible risk of laryngospasm, and higher costs [3].

Previous studies using propofol and opioids during MAC set specific concentrations of propofol and compared several levels of opioids. Heo et al. [14] infused propofol at a rate of 3.2-3.4 $\mathrm{mg} / \mathrm{kg} / \mathrm{h}$ and compared two infusion rates of remifentanil: 0.05 versus $0.1 \mu \mathrm{g} / \mathrm{kg} / \mathrm{min}$. The results showed that $0.05 \mu \mathrm{g} / \mathrm{kg} / \mathrm{min}$ provided appropriate analgesia without respiratory depression. Ryu et al. [16] used a TCI system, infused propofol at a Ce of $1.0 \mu \mathrm{g} / \mathrm{ml}$, and compared three Ce values of remifentanil -0.5 , 1.0 , and $1.5 \mathrm{ng} / \mathrm{ml}$ - during cataract surgery. It was found that $1.0 \mathrm{ng} / \mathrm{ml}$ Ce of remifentanil provided optimal conditions. Lee et al. [15] performed MAC during carpal tunnel release surgery, infusing propofol $2.0 \mu \mathrm{g} / \mathrm{ml}$ using a TCI pump and compared three infusion rates of remifentanil: $0.05,0.07$, and $0.1 \mu \mathrm{g} / \mathrm{kg} /$ $\mathrm{min}$. They reported that $0.07 \mu \mathrm{g} / \mathrm{kg} / \mathrm{min}$ was the optimal dose without adverse events.

However, we had empirical considerations from clinical practice that the level of consciousness, respiration, and pain responses could be altered by small changes in target concentrations, such as $0.2 \mu \mathrm{g} / \mathrm{ml}$ propofol and $0.2 \mathrm{ng} / \mathrm{ml}$ remifentanil during deep sedation. Thus, in this research, we chose the method of changing target concentration based on the patient's condition manually, rather than preset concentrations of the drugs.

There was only one patient who did not request $\mathrm{O}_{2}$. He needed $0.9 \mu \mathrm{g} / \mathrm{ml}(2.49 \mathrm{mg} / \mathrm{kg} / \mathrm{h})$ and $1.5 \mathrm{ng} / \mathrm{ml}(0.06 \mu \mathrm{g} / \mathrm{kg} / \mathrm{min})$ maximum Ce values of propofol and remifentanil, respectively, and his BIS was maintained at 72-79 during surgery. Three studies that were mentioned earlier gave $\mathrm{O}_{2}$ through a mask or nasal prong to every patient [14-16]. The authors of these studies reported that $2-15 \%$ of patients showed desaturation during surgery. A much larger proportion of patients, $40 \%$, suffered respiratory depression in this trial. The strict criterion of desaturation $\left(\mathrm{SpO}_{2}<95 \%\right)$ in our trial versus the other three studies $\left(\mathrm{SpO}_{2}<90 \%\right.$ or $\left.92 \%\right)$ may have contributed to the higher rate of respiratory depression. Additionally, airway manipulation, such as a chin lift, was not described in these studies. Thus, it might not be fair to compare the proportion of patients directly, but we think the higher respiratory support rate was because we intervened promptly when a patient was seen to be going into respiration depression.

In the three earlier studies, the higher the remifentanil concentration infused, the more patients were desaturated [14-16]. However, in our study, the target concentration of the drugs did not affect whether patients required respiratory support. Changing the target concentration of both drugs was designed to resemble normal clinical practice, but it may be a reason for the insignificant difference. The lowest maximum Ce values of propofol and remifentanil were $0.3 \mu \mathrm{g} / \mathrm{ml}(0.55 \mathrm{mg} / \mathrm{kg} / \mathrm{h})$ and 0.9 $\mathrm{ng} / \mathrm{ml}(0.03 \mu \mathrm{g} / \mathrm{kg} / \mathrm{min})$, respectively, in the same patient. This male patient received supported respiration up to the CL step. This indicates that even a low Ce can bring about respiratory depression. From these results, we can advise that physicians should have an awareness of unpredictable respiratory depression and provide attention and careful monitoring during deep sedation to avoid adverse events.

The only factor that was different between the groups by respiration assist method was age. The AV group (46.3) was younger than the non-AV group (53.6). We did an additional analysis of the relationship between age and target concentration. $\mathrm{Pa}-$ tients who were aged 50 or older required a lower maximal Ce of propofol $(1.08 \pm 0.40 \mu \mathrm{g} / \mathrm{ml})$ than patients who were younger than $50(1.41 \pm 0.51 \mu \mathrm{g} / \mathrm{ml} ; \mathrm{P}=0.014)$. The maximal Ce of remifentanil was similar between the two groups by age. In terms of assisted ventilation, the older ( $\geq 50$ years of age) group showed a significantly lower rate of $\mathrm{AV}(26.7 \%)$ than the younger $(<50$ years of age) group (57.1\%; $\mathrm{P}=0.028)$. We can infer from these results that propofol may contribute to the difference between the $\mathrm{AV}$ and non-AV groups.

No patient complained of nausea or vomiting. Continuous changing of the Ce with feedback from the patient's condition resulted in a low total infusion dose and no adverse effects of the opioid. Additionally, patient satisfaction scores were very high.

The current study has several limitations. First, it was unclear which factor(s) may play a role in respiratory depression. Second, this was an observational study rather than a randomized controlled trial. Additionally, although there was no patient who could not be ventilated with a mask, it would have been interesting if there was an advanced option in the respiratory assist steps including application of airway devices for a 'cannot ventilate' situation. A well-designed randomized controlled study will be necessary in the future to determine the relationship between age and respiratory depression during deep sedation.

In summary, MAC during saphenous vein stripping surgery with propofol and remifentanil infusion after midazolam injection and $2 \%$ lidocaine skin infiltration is useful for ambulatory surgery because intubation is not necessary, it barely causes nausea/vomiting, fast recovery and early discharge are possible, and it increases patient satisfaction. However, $82 \%$ of patients needed respiratory assistance, including chin lift and assisted ventilation with a mask, and in almost every patient (except one), $\mathrm{O}_{2}$ supply was essential. Furthermore, preparation of airway devices is required.

In conclusion, excellent patient satisfaction was achieved using low infusion rates of propofol and remifentanil under MAC during vein stripping surgery, but close monitoring and care are necessary. 


\section{References}

1. Vloka JD, Hadzić A, Mulcare R, Lesser JB, Kitain E, Thys DM. Femoral and genitofemoral nerve blocks versus spinal anesthesia for outpatients undergoing long saphenous vein stripping surgery. Anesth Analg 1997; 84: 749-52.

2. Vloka JD, Hadzic A, Mulcare R, Lesser JB, Koorn R, Thys DM. Combined popliteal and posterior cutaneous nerve of the thigh blocks for short saphenous vein stripping in outpatients: an alternative to spinal anesthesia. J Clin Anesth 1997; 9: 618-22.

3. Arun O, Oc B, Duman A, Yildirim S, Simsek M, Farsak B, et al. Endovenous laser ablation under general anesthesia for day surgery: feasibility and outcomes of the 300 patients. Ann Thorac Cardiovasc Surg 2014; 20: 55-60.

4. Moon EJ, Kang KW, Chung JY, Kang JM, Park JH, Joh JH, et al. The comparison of monitored anesthesia care with dexmedetomidine and spinal anesthesia during varicose vein surgery. Ann Surg Treat Res 2014; 87: 245-52.

5. Keith LM Jr, Smead WL. Saphenous vein stripping and its complications. Surg Clin North Am 1983; 63: 1303-12.

6. Savoia G, Loreto M, Gravino E, Canfora G, Frangiosa A, Cortesano P, et al. Monitored anesthesia care and loco-regional anesthesia. Vascular surgery use. Minerva Anestesiol 2005; 71: 539-42.

7. Sá Rêgo MM, Watcha MF, White PF. The changing role of monitored anesthesia care in the ambulatory setting. Anesth Analg 1997; 85: 1020-36.

8. Rosow C. Remifentanil: a unique opioid analgesic. Anesthesiology 1993; 79: 875-6.

9. Eikaas H, Raeder J. Total intravenous anaesthesia techniques for ambulatory surgery. Curr Opin Anaesthesiol 2009; $22:$ 725-9.

10. Bhananker SM, Posner KL, Cheney FW, Caplan RA, Lee LA, Domino KB. Injury and liability associated with monitored anesthesia care: a closed claims analysis. Anesthesiology 2006; 104: 228-34.

11. Vuyk J, Sitsen E, Reekers M. Intravenous Anesthetics. In: Miller's Anesthesia. 8th ed. Edited by Miller RD: Philadelphia, Churchill Livingstone/Elsevier. 2015, pp 821-63.

12. Fukuda K. Opioid analgesics. In: Miller's Anesthesia. 8th ed. Edited by Miller RD: Philadelphia, Churchill Livingstone/Elsevier. 2015, pp 864-914.

13. Preston CC, Colman AM. Optimal number of response categories in rating scales: reliability, validity, discriminating power, and respondent preferences. Acta Psychol (Amst) 2000; 104: 1-15.

14. Heo HJ, Han JI, Kim CH, Lee GY. Optimal infusion rates of remifentanil during propofol anesthesia for monitored anesthesia care in patient undergoing varicose vein endovenous laser therapy. Korean J Anesthesiol 2008; 54: 411-5.

15. Lee JJ, Hwang SM, Jang JS, Lim SY, Heo DH, Cho YJ. Remifentanil-propofol sedation as an ambulatory anesthesia for carpal tunnel release. J Korean Neurosurg Soc 2010; 48: 429-33.

16. Ryu JH, So YM, Hwang JW, Do SH. Optimal target concentration of remifentanil during cataract surgery with monitored anesthesia care. J Clin Anesth 2010; 22: 533-7.

17. Armellin G, Baccaglini U, Castoro C, Ori C. Deep sedation and local anaesthesia: a safe and suitable association for outpatients undergoing vein stripping. Ambul Surg 2007; 13: 111-3.

18. Hong JY, Kang YS, Kil HK. Anaesthesia for day case excisional breast biopsy: propofol-remifentanil compared with sevoflurane-nitrous oxide. Eur J Anaesthesiol 2008; 25: 460-7.

19. Ghisi D, Fanelli A, Tosi M, Nuzzi M, Fanelli G. Monitored anesthesia care. Minerva Anestesiol 2005; 71: 533-8.

20. Smith I, Skues M, Philip BK. Ambulatory (outpatient) anesthesia. In: Miller's Anesthesia. 8th ed. Edited by Miller RD: Philadelphia, Churchill Livingstone/Elsevier. 2015, pp 2612-45. 